\title{
Cyclostationary Analysis towards Fault Diagnosis of Rotating Machinery
}

\author{
Shengnan Tang ${ }^{1}\left(\mathbb{D}\right.$, Shouqi Yuan ${ }^{1, *}$ and Yong Zhu ${ }^{1,2,3, *(1)}$ \\ 1 National Research Center of Pumps, Jiangsu University, Zhenjiang 212013, China; tangsn6635@126.com \\ 2 State Key Laboratory of Fluid Power and Mechatronic Systems, Zhejiang University, \\ Hangzhou 310027, China \\ 3 Ningbo Academy of Product Quality Inspection, Ningbo 315048, China \\ * Correspondence: shouqiy@ujs.edu.cn (S.Y.); zhuyong@ujs.edu.cn (Y.Z.); Tel.: +86-0511-88780280 (S.Y.); \\ +86-0511-88799918 (Y.Z.)
}

Received: 23 August 2020; Accepted: 23 September 2020; Published: 28 September 2020

\begin{abstract}
In the light of the significance of the rotating machinery and the possible severe losses resulted from its unexpected defects, it is vital and meaningful to exploit the effective and feasible diagnostic methods of its faults. Among them, the emphasis of the analysis approaches for fault type and severity is on the extraction of useful components in the fault features. On account of the common cyclostationarity of vibration signal under faulty states, fault diagnosis methods based on cyclostationary analysis play an essential role in the rotatory machine. Based on it, the fundamental definition and classification of cyclostationarity are introduced briefly. The mathematical principles of the essential cyclic spectral analysis are outlined. The significant applications of cyclostationary theory are highlighted in the fault diagnosis of the main rotating machinery, involving bearing, gear, and pump. Finally, the widely-used methods on the basis of cyclostationary theory are concluded, and the potential research directions are prospected.
\end{abstract}

Keywords: cyclostationarity; cyclic spectral; fault diagnosis; rotating machinery

\section{Introduction}

In practical engineering, owing to the changeable operation conditions of widely used rotating machinery, it is difficult to avoid the resulting faults of the components or system. In order to reduce the economic losses and security risks caused by the faults, it is of great significance to conduct the study of fault diagnosis methods [1-4].

In mechanical faulty conditions, different degrees of vibration can be produced, such as harmonics, impulse response signals generated by wear and break, and noise signals generated by measurement [5-7]. Vibration analysis has many strengths, including the easy online implementation and fast change response in varying conditions [8,9]. Hence, the analysis of vibration signal is conventionally employed for diagnosis and prediction. The acquired signal includes deterministic components and stochastic signal, and the latter is classified into stationary and non-stationary signals. Therefore, the approaches of feature extraction involve stationary and non-stationary analysis based on the machinery vibration signal [10-12]. In light of the limitations of the characteristic representation of the stationary methods and the non-stationarity of the fault signature, non-stationary methods have been an attractive choice for the extraction of fault information with high precision in rotary machinery.

Some methods based on the time-frequency domain analysis have been successfully applied to the processing of non-stationary signals, such as short-time Fourier transform (STFT), wavelet transformation (WT), Wigner-Ville distribution, and cyclic statistical analysis [13-16]. It is of great difficulty to investigate an effective method for the processing of nonlinear signals [17]. As a typical 
rising development of the signal processing techniques, cyclostationary (CS) approaches present the admirable advantages in analyzing the signature with the characteristics of the nonlinearity, non-Gaussian, and non-stationarity [18-20]. The concept of cyclostationarity was firstly proposed by W.R. Bennett, indicating that the periodicity of signal could be well concealed in the non-stationary processes [21]. Compared with normal signals, faulty signals produce periodic component or modulation phenomenon, and the statistics present periodic transformation. Strictly, CS is defined as a joint probability density function where the time series possess periodic time varying. When the statistical characteristics show periodic or multiperiodic stationary changes, it can be named as CS. Since Gardner firstly proposed the feature of the CS signal, it has aroused the interests of the researchers in the field of the fault diagnosis of rotating machinery [22-24]. Akhand Rai et al. analyzed and discussed the progress of signal processing techniques according to the different periods of the researches [25]. CS analysis was applied in the discussed second stage, and the new developments of enhanced and combined methods were demonstrated as well in the third stage [26-28].

In terms of the characteristics of the vibration signal of rotating machinery, it can be viewed as CS signal when machinery faults happen [29]. In consideration of the periodicity and randomness of vibration signal, Sawalhi et al. employed the cyclostationarity and relative functions for the fault diagnosis of gearbox, constructing the corresponding model for simulation [30]. The strategy of the bispectral domain was used for the fault analysis of rotating machinery [31]. J. Antoni et al. analyzed the varying CS components of different rotating machinery including bearing and gearbox and discussed the relationship between angle domain and time cyclostationarity; moreover, a method was investigated combined blind deconvolution and demonstrated the validity and feasibility under the effects of the noise and speed [32-35]. Motivated by the research of J. Antoni, the CS analysis was performed in bearing fault diagnosis under the non-stationary situations, the influence of the working load and speed fluctuation included [36]. To analyze the squared envelope spectrum of signals, second order CS components (a colored noise carrier modulated by a periodic signal, and the added colored background noise) were separated and investigated for the bearing fault diagnosis [37]. Zhou et al. employed the CS theory for the fault diagnosis of rolling bearing [38]. He et al. studied the first-order cyclostationarity of the fault signal in gear and the second-order cyclostationarity of the bearing. Moreover, the potential mechanism was analyzed and discussed [39]. On the basis of the enhanced cyclical spectrum, a new method was developed to achieve the extraction of fault feature of bearing [40]. A new methodology based on the CS analysis was established for the gearbox diagnostics [41].

CS processing methods have made desirable achievements in the application of fault diagnosis towards the rotary machines. With respect to the superiority of the CS analysis in non-stationary signal processing, this review plays an emphasis on the main and widely-used rotating machinery, involving bearing, gearing and pump. The highlighted methods include the cyclic spectral correlation (CSC), cyclic spectral coherence (CSCoh), and some integrated methods to promote the performance of fault diagnosis. Especially, the applications of the analysis methods discussed above are analyzed and discussed on intelligent fault diagnosis for rotating machinery. This research provides a novel perspective for the fault feature extraction of non-stationary signal and the exploration of the new diagnostic methods.

\section{Basic Theory of Cyclostationarity}

In terms of the traditional signal processing methods, the vibration signal is conventionally employed to accomplish the condition monitoring and fault diagnosis [42]. In healthy condition, the acquired signal is usually viewed to be stational for the sequent analysis. However, owing to the effect of the fluctuation of working load and environmental noise in faulty condition, non-stationary signal could be obtained in most practical situations [43-46]. The CS analysis is exactly an effective tool for the processing non-stational signal. It could be employed for the feature extraction, condition monitoring, and fault identification [47,48]. Moreover, the vibration signal containing faults of rotating machinery possesses non-stationarity, which provides a potential development for CS analysis $[49,50]$. 
Through the CS analysis, the significant hidden feature information can be revealed, and the different information denotes the changeable fault conditions.

\subsection{Definition of Cyclostationarity}

Generally, the signals whose statistical characteristics are periodic or multi-periodic (each cycle cannot be generalized) are referred to as CS or periodic stationary. The rotating machine operates in a rotating way, which will produce periodic signals under normal running process. When the machinery fault occurs, its vibration signal can be considered as a modulation signal. Its second-order statistics (mainly cyclic autocorrelation function, spectral correlation function, and spectral coherency function) present the periodicity and thus can be viewed as a CS signal, which is a special non-stational signal [51].

Definition 1. Strict cyclostationarity

As for the random process of $x(t)$, the probability density function of the $k$ dimensional variable can be represented as follows:

$$
f\left(x\left(t_{1}\right), x\left(t_{2}\right), \cdots x\left(t_{k}\right)\right)=f\left(x\left(t_{1}+L_{1} T\right), x\left(t_{2}+L_{2} T\right), \cdots x\left(t_{k}+L_{k} T\right)\right),
$$

Among them, $L_{i},(i=1,2, \cdots, k)$ denotes any integer, $L_{1} \neq L_{2} \neq \ldots \neq L_{k}$, and $T$ represents sampling period. So, the process can be named strict cyclostationarity.

\section{Definition 2. Generalized almost cyclostationarity}

If the random process of $x(t)$ presents the periodic or multi-periodic stationary change, it can be called generalized almost cyclostationarity (GACS). The cyclostationarity involved in the most researches are based on the GACS.

\subsection{The Classification of Cyclostationarity}

In accordance with the periodic change of the signature, this process can be classified into the following three processes: the first-order, the second-order, and the higher order.

When the first moment $m_{x}(t)$ of random process $x(t)$ satisfies the following condition:

$$
m_{x}(t)=m_{x}(t+T) .
$$

This can be named the first-order cyclostationarity.

Suppose that the autocorrelation function of $x(t) R_{x}(t, \tau)$ conforms to the following situation:

$$
R_{x}(t, \tau)=R_{x}\left(t+T+\frac{\tau}{2}, u+T-\frac{\tau}{2}\right) .
$$

This can be called the second-order cyclostationarity.

If the $k(k \geq 3)$ moment $m_{k x}\left(t, \tau_{1}, \tau_{2}, \cdots, \tau_{k-1}\right)$ meets the following descriptions,

$$
m_{k x}\left(t, \tau_{1}, \tau_{2}, \cdots, \tau_{k-1}\right)=m_{k x}\left(t+T, \tau_{1}, \tau_{2}, \cdots, \tau_{k-1}\right) .
$$

This can be named the higher-order cyclostationarity, including the third-order cyclostationarity $[52,53]$.

In terms of the second-order cyclostationarity, the instantaneous autocorrelation function of $x(t)$ can be expressed as:

$$
R_{x}(t, \tau)=E\left\{x\left(t+\frac{\tau}{2}\right) x^{*}\left(t-\frac{\tau}{2}\right)\right\},
$$

where $\tau$ denotes the lag time, $E\{\}$ denotes the mathematical expectation, and * means the complex conjugate. 
If the $T$ is taken as the period of $R_{x}(t, \tau)$, Then,

$$
R_{x}(t, \tau)=R_{x}(t+T, \tau),
$$

It can be represented as the form of Fourier series:

$$
R_{x}(t, \tau)=\sum_{\alpha} R_{x}^{\alpha}(\tau) e^{j 2 \tau x t},
$$

Thereinto, $\alpha=m / T, m \in Z$, the Fourier coefficient of $R_{x}(t, \tau)$ can be given by:

$$
R_{x}^{\alpha}(\tau)=\frac{1}{T} \int_{-T / 2}^{T / 2} R_{x}(t, \tau) e^{j 2 \tau x t} d t,
$$

$R_{x}^{\alpha}(\tau)$ is called the cyclic autocorrelation, $\alpha$ denotes the cyclic frequency.

Further, take the Fourier transform of $R_{x}^{\alpha}(\tau)$, then,

$$
S_{x}^{\alpha}(f) \triangleq \int_{-\infty}^{\infty} R_{x}(t, \tau) e^{j 2 f x t} d t .
$$

$S_{x}^{\alpha}(f)$ is defined as the spectral correlation density function or the spectral correlation function. In the above expression, $f$ denotes the spectral frequency which is distinct from the cyclic frequency defined before [54].

\section{Applications of Cyclostationarity Theory in Fault Diagnosis of Rotating Machinery}

In accordance with the basic theory of cyclostationarity, it has been applied in many research fields, involving signal processing, econometrics, mechanics, and biology [55-57]. Lots of direct and combined approaches have been exploited for the fault diagnosis of rotating machinery [58-60]. It is noted that variable operational conditions are studied in some analysis methods [61-63]. In the light of the advantages in the nonstationary signal analysis, spectral correlation has been successfully used for bearing fault diagnosis [64-66]. Furthermore, the CSC and CSCoh were employed to diagnose the fault of bearing. Inspired by the development and application of artificial intelligence, the intelligent diagnostic method was investigated combined machine learning techniques with cyclostationarity. In addition, sparse test-based integrated methods and energy slice bispectrum-based methods were used for bearing fault diagnosis. On account of the ratio of cyclic content and harmonic-to-noise ratio, a new diagnostic approach was studied as well. In consideration of the noise cancellation, relative improved methods were constructed. Moreover, the enhanced envelope spectrum was utilized for the wind turbine gearbox.

Owing to the advantages of cyclic spectral analysis, it plays a pivotal role in the CS signature processing of machinery [67-69]. CSC is a two-domain function, manifesting the relationship between the spectral frequency and the cyclic frequency. Compared with traditional cyclic spectral analysis, CSCoh presents the superiority in the presence of noise interference, which has been demonstrated to be more efficacious for the processing of CS signals [70,71].

By integrating CSCoh and envelope spectrum, Mauricio et al. developed two methods to select the optimal frequency band for the bearing fault diagnosis: improved envelope spectrum by alpha maximization (IESAM) and improved envelope spectrum via feature optimization-gram (IESFOgram), respectively [72]. The raw time signal was transformed into bispectral map in both methods. IESAM was employed to acquire the specific frequency band on condition that the characteristic fault frequency required to be gained. In comparison to other processing methods, it presents the superiority with respect to the computational capability. The shortcoming of this method was that the preprocessing step consumed a longer time. As one of the methods similar to the Fast Kurtogram, IESFOgram was used to achieve the optimization of the amplitude. Although it presents enhanced performance, it is 
disadvantageous in terms of both the computing cost and operation time. Moreover, the IESFOgram method was extended to accomplish the extraction of the combined improved envelope spectrum, adding the information of other bands. In comparison with the band pass filtering selection based on the Fast Kurtogram-based squared envelope spectrum (SES) and the Autogram-based combined squared envelope spectrum (CSES), it presents better performance in detecting the characteristic frequencies of bearing and gearbox [73].

The methods of band selection in CS analysis were also investigated in the fault diagnosis of rotating machinery [74,75]. To achieve the separation of cyclostationarity from non-Gaussianity, an analysis tool based on the log-cycligram was constructed for the selection of the optimal demodulation band. The diagnostic performance of the method was validated through bearing experiments and other existing methods were employed for comparisons [76]. The effectiveness in band selection of both the methods was validated through the application to the bearing fault diagnosis. BPFI denotes the characteristic inner race defect frequency. To obtain different fault data, varying moments of force were added for the deformation of bearing. Three cases were performed with loads 30, 50, and $70 \mathrm{Nm}$. The results with load $50 \mathrm{Nm}$ were analyzed as an example. As shown in Figure 1, through correctly seeking for the optimal band, the fault frequencies of bearing in different conditions were obtained by the identification of the harmonics of the fault component. From Figure 2 it can be found that two distinct fault feature values were located in around $42 \mathrm{kHz}$, which showed the comparability to the results of IESAM methods.

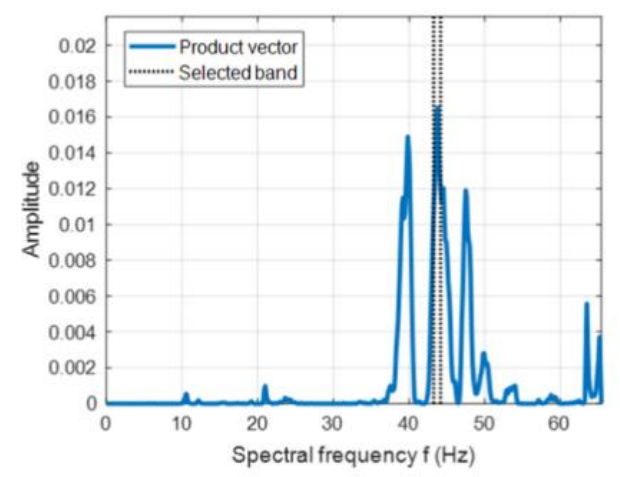

(a) IESAM criterion for band selection.

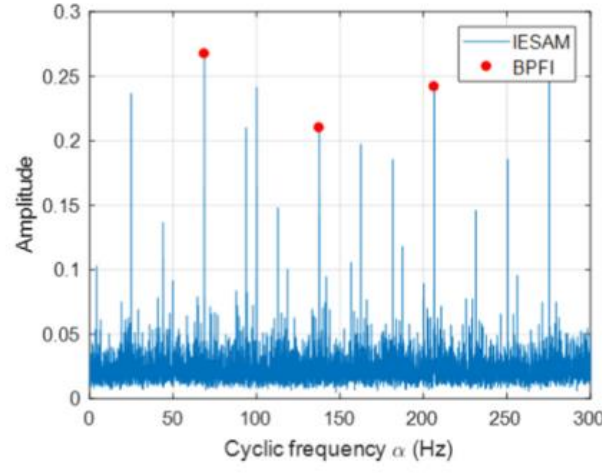

(b) Resulting IESAM.

Figure 1. IESAM method applied to inner race fault with load $50 \mathrm{Nm}$. IESAM denotes improved envelope spectrum by alpha maximization.

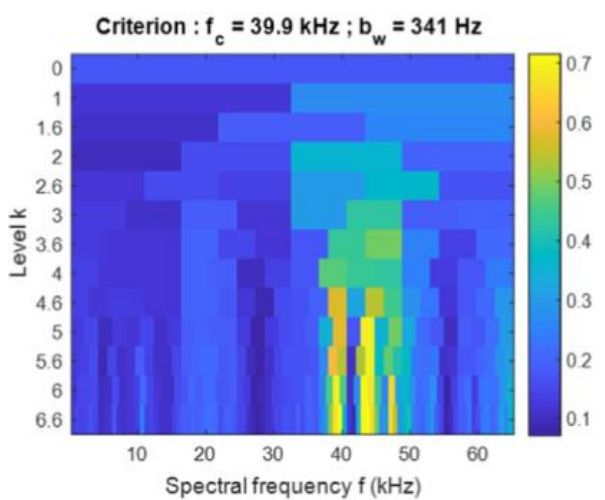

(a) IESFOgram.

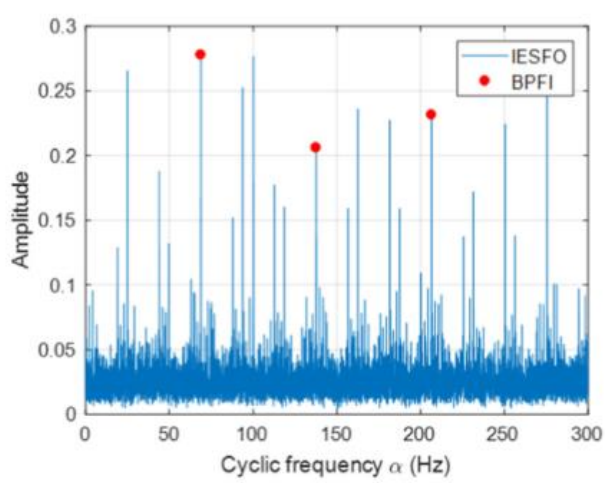

(b) Resulting IESFO.

Figure 2. IESFO method applied to inner race fault with load $50 \mathrm{Nm}$. IESFO means improved envelope spectrum via feature optimization. IESFOgram means improved envelope spectrum via feature optimization-gram. 
Inspired by the application of CSCoh in signature processing, Chen et al. employed it as a tool of feature extraction to the intelligent fault diagnosis of bearings based on convolutional neural network (CNN) [77]. Raw vibration data were processed to accomplish the preliminary feature learning of fault information and obtain the distinguished features, which could make the subsequent feature learning of CNN less difficult to some extent. Specifically, a special conversion was achieved from raw data into two-dimensional spectrogram, which was taken as the data input of the developed CNN. The concealed periodic variation behavior of fault data was revealed through the combination of the preprocessing and classification methods. To be more consistent with practical different noise levels, white Gaussian noise were added on the raw signals with a SNR of 4 and $0 \mathrm{~dB}$. Moreover, diverse signal analysis methods were employed for data preprocessing. The integrated approach achieved an average accuracy of $99.02 \%$, which was superior to other approaches by the use of different time-frequency analysis methods under changing situations, including STFT and WT (Table 1).

Table 1. Comparison of average accuracy with different time-frequency analysis methods in varying working conditions.

\begin{tabular}{ccc}
\hline Time-Frequency Analysis Methods & Signal to Noise Ratio (SNR) & Average Accuracy (\%) \\
\hline \multirow{2}{*}{ short-time Fourier transform (STFT) } & --- & 95.20 \\
& $4 \mathrm{~dB}$ & 90.44 \\
& $0 \mathrm{~dB}$ & 87.98 \\
\hline \multirow{2}{*}{ wavelet transformation (WT) } & -- & 95.32 \\
& $4 \mathrm{~dB}$ & 88.51 \\
& $0 \mathrm{~dB}$ & 86.34 \\
\hline \multirow{2}{*}{ cyclic spectral coherence (CSCoh) } & -- & 99.02 \\
& $4 \mathrm{~dB}$ & 94.97 \\
\hline
\end{tabular}

With an integration of popular machine learning methods and CS analysis, an intelligent diagnostic method was carried out for fault diagnosis of rolling element bearing [78-80]. The CSC and CSCoh were exploited to convert the time signals into the spectral features, which achieved the establishment of healthy indicators (Figure 3). Compared with other indicators, the indicators constructed showed the superior robustness. A semi-supervised learning method based on the support vector data description (SVDD) was used to accomplish the classification of the extracted features. Negative samples were obtained by constructing artificial outliers using an object-generation method. Support vector data description with negative samples was named NSVDD. Three different levels were employed to train the model, namely sensor level, machine level, and fleet level. It was demonstrated that the method presented the preferable classification effectiveness for bearing faults.

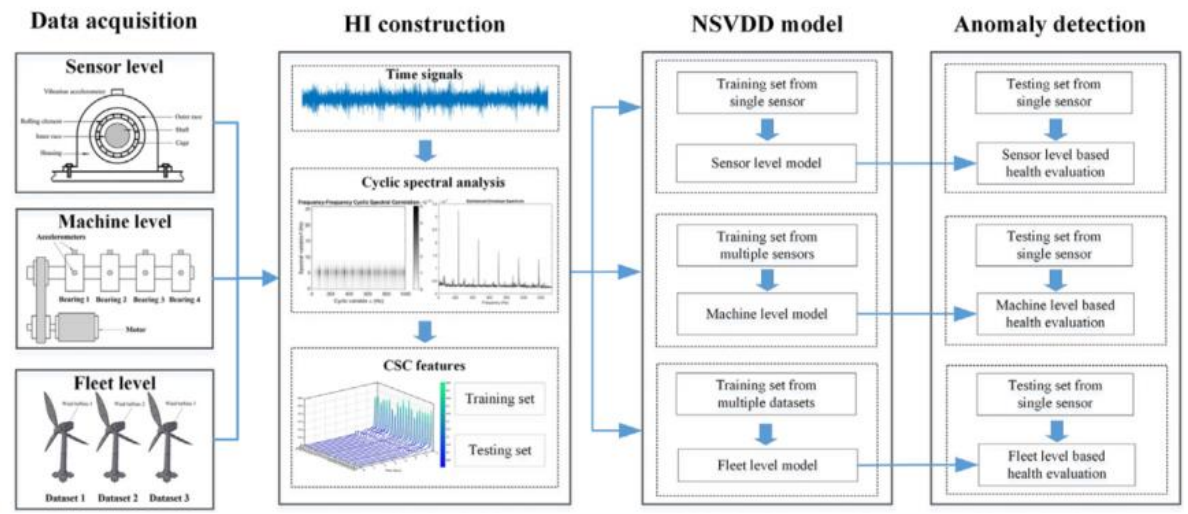

Figure 3. The anomaly detection framework with NSVDD model, evaluated on three levels: (i) Sensor level, (ii) machine level, and (iii) fleet level. NSVDD denotes support vector data description with negative samples. 
On account of the screening of the effective spectral frequency and the reliance of spectral correlation/spectral coherence on the special experience, a simple method was performed based on the sparse test for bearing fault diagnosis [81]. It is demonstrated that this method is effective even in condition of weak fault frequencies and serious interferences from other cyclic frequencies. The method was considered as a guideline for the acquisition of the enhanced envelop spectrum, which outperformed the other approaches for comparisons. Figure $4 \mathrm{a}, \mathrm{b}$ displays the raw signal and the corresponding frequency-domain distribution under inner race fault condition, respectively. Owing to the limitations of the acquisition device, some large signal amplitudes show the flat trend. As shown in Figure $4 c$, spectral coherence of the signal is obtained according to the previous research, indicating the relationship of cyclic frequency and spectral frequency. But it is hard to complete the fault diagnosis only by spectral coherence due to the interference of other components. By the use of the guideline, two obvious hills are found in Figure 4d, around 2000 and $5000 \mathrm{~Hz}$, respectively. By combing the above analysis, Figure 4e depicts the EES obtained from the spectral frequency band from 1564 to $2030 \mathrm{~Hz}$, and the bearing inner race fault can be observed. Similarly, Figure $4 \mathrm{f}$ displays the EES obtained from the spectral frequency band from 4793 to $5259 \mathrm{~Hz}$, and no useful information is acquired for fault diagnosis.
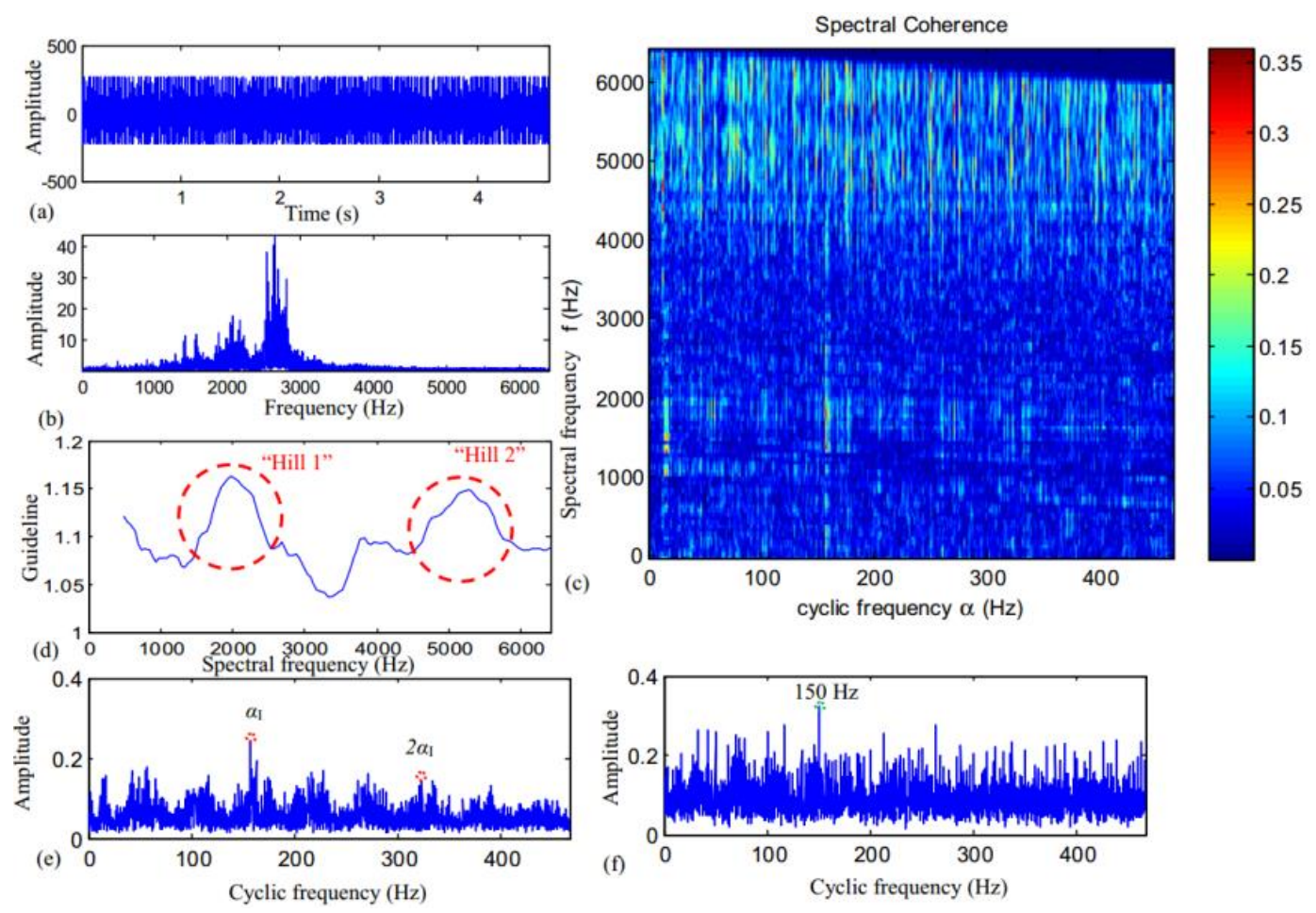

Figure 4. Results obtained by using the proposed method for processing an industrial inner race fault signal: (a) A raw inner race fault signal; (b) frequency spectrum of (a); (c) spectral coherence of the inner race fault signal; (d) the proposed guideline; (e) EES obtained by integrating spectral coherence over a spectral frequency band from 1564 to $2030 \mathrm{~Hz}$; (f) EES obtained by integrating spectral coherence over a spectral frequency band from 4793 to $5259 \mathrm{~Hz}$. EES represents an enhanced envelope spectrum.

Through the combination of the adaptive CS blind deconvolution and instantaneous energy slice bispectrum, a new method was developed to achieve the signal separation and further fault feature extraction of wind turbine bearing [82]. It is worth mentioning that the cuckoo search algorithm was employed for parameter optimization. It could be concluded that the external inference was successfully reduced with the method from the clear obtained characteristic frequencies. It was testified that this novel diagnostic method outperformed the other methods such as minimum entropy deconvolution and maximum correlated kurtosis deconvolution. With the assistance of different periodicity detection 
techniques, Chen et al. used maximum second-order CS blind deconvolution for the enhancement of bearing fault feature [83]. To complete the fault diagnosis of rolling element bearing, Ming et al. employed a simplified method of the CS called spectral auto-correlation analysis for extracting the fault characteristic frequency [84].

Different from the conventional researches in single fault, compound fault diagnosis methods were investigated based on the CS analysis with a combination of other techniques. In view of the pseudo-CS analysis of the bearing fault conducted by some researches, a new combined diagnosis analysis method was constructed based on the ratio of cyclic content, harmonic-to-noise ratio, and CS analysis [85-87]. In comparison with the spectral Gini index and spectral kurtosis, the method displayed the advantage in both single fault diagnosis and compound fault diagnosis of bearing. By using the second order CS and the discolored cyclic harmonic ratio, Luo et al. established a new index including the information of fault characteristic frequency. In place of fast Kurtogram, the Meyer wavelet filters of empirical wavelet transform were used owing to the advantages in spectrum separation and localization of time and frequency. The effectiveness and feasibility of the method are demonstrated on planetary gearbox and rolling bearing [88].

Similar methods have been applied in the condition monitoring of gear [89-91]. As a way of extracting the periodic components hidden in noise, the analytical methods based on autocorrelation were employed for gear and gearbox fault diagnosis [92,93]. In order to extract single CS component of interest from complex sources, the methods of filtering the raw signals are worth further exploring [94-96]. Inspired by this bottleneck in signal processing, a new stochastic model for CS signals was built for the gear fault diagnosis [97]. For the purpose of the comprehensive and complex modulation information of local faults in planetary gear, a novel analysis method was established on the basis of the self-adaptive noise cancellation approach and CSCoh analysis [98]. It was worth pointing out that the influences of rotating speed fluctuation were taken into account. It was demonstrated that the fault features of the vibration signals were uncovered via the constructed CS model. Motivated by the previous research on the wind turbine gearboxes, Mauricio et al. employed IESFOgram for the condition monitoring of the planetary gearbox with multiple vibration sources. It is indicated that this method can promote the reliability of the complicated helicopters and provide the evidences for the following maintenance $[99,100]$.

On consideration of the complexity of CSC and CSCoh analysis, an improved method called the enhanced envelope spectrum was employed for the fault diagnosis of wind turbine gearbox [101]. It was demonstrated that the method could effectively identify the characteristic frequencies of a wind turbine gearbox in comparison with other processing approaches (Figure 5).

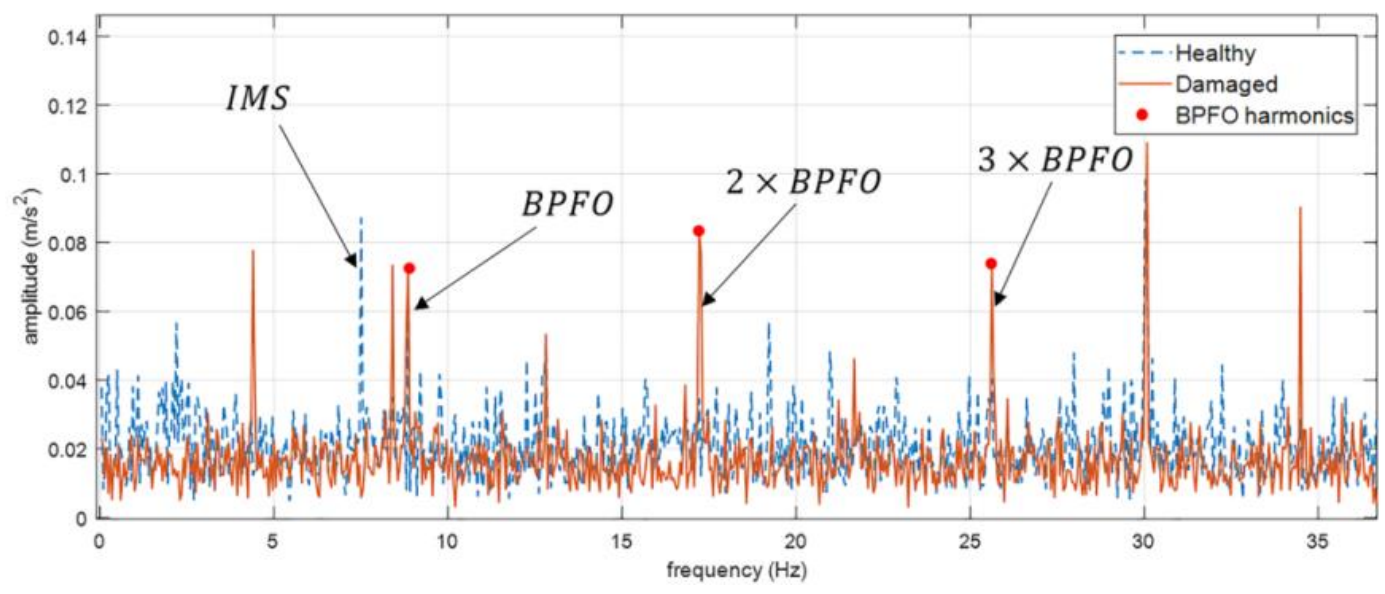

Figure 5. EESFO for the BPFO detection of the PLC upwind bearing damage corresponding to sensor AN5. EESFO represents the enhanced envelope spectrum by feature optimization, BPFO represents the ball pass frequency outer race, PLC represents planet carrier, and AN5 denotes a sensor. 
In machinery fault diagnosis, external interferences may make it difficult to accomplish the accurate and effective fault diagnosis, including background noise and interfering signals. Xin et al. conducted an analysis method for the extraction of CS signal of interest and applied it for the fault diagnosis of a wind turbine gearbox, taking the external influences into account. A periodic-variance based model was used for the extraction of the desired CS signal. Moreover, the method can be extended to gears and bearings, and applied to many kinds of modulations in a mechanical system [97].

In the light of non-stationarity of vibration signals for pumps, a CS analysis-based method was developed through three different techniques of cyclic autocorrelation, slices analysis, and FFT. The information on the characteristic frequencies of centrifugal pump was effectively identified from the raw signature [102].

As a key component in most hydraulic systems, the fault diagnosis methods of an axial-piston pump are very significant. On the strength of the fundamental CS theory and varying situations, the acquired acceleration signal was separated, and a new method of feature extraction was developed for the fault diagnosis of axial-piston pump [103]. As for the residual signals, first-order analysis of time domain and frequency domain was conducted by the calculation of the synchronous average and FFT. In view of the second-order analysis, the spectral correlation density and the cyclic spectral coherence were performed.

\section{Conclusions and Perspectives}

Many researches based on the CS theory have been demonstrated to be efficient and feasible, which outperform the other analysis approaches in the revelation of the useful components of the fault signature [104-107]. With the improvement of the signal processing techniques, more and more integrated methods are investigated mainly for the analysis of the single fault $[108,109]$.

Some researchers embark on the exploration of the diagnosis of the compound fault. Moreover, the external influences are taken into consideration, including the variation of speed and the noise. It is more consistent with the engineering practice, which is more conducive to the extension of the methods in practice.

The significant applications of CS are analyzed and evaluated in typical representatives of the rotating machinery, including bearing, gear, and pump. On account of the strengths of cyclic spectral analysis, CSC and CSCoh are successfully employed to enhance the diagnostic performance of bearings. Combined CSC or CSCoh with envelope spectrum, IESAM and IESFOgram are performed for the automatic selection of the optimal frequency band under strong electromagnetic interference. Even in the case of varying loads, the outer race and inner race fault of bearings of complex helicopters can be detected. It is indicated that it can be extended to more challenging conditions.

Motivated by the researches of CSCoh on traditional fault diagnosis, it is introduced into the intelligent diagnostic methods based on machine learning and deep learning. The integrated methods make full use of the advantages of single approach, involving the preprocessing of CSCoh and the automatic learning capability of useful features of CNN and SVDD. The desirable diagnostic accuracy is obtained.

In order to overcome the strong interferences on the identification of fault characteristic frequency, CS-based methods can be applied to weak fault diagnosis via the acquisition of the enhanced envelop spectrum. Further, the extraction of CS signal of interest can be generalized to gears and bearings.

CS analysis is a powerful tool for the fault diagnosis of rotating machinery. Especially, CSC and CSCoh present the special superiority in many cases. However, most of the above methods are employed in traditional fault diagnosis; the researches on intelligent diagnosis are still few. On account of the complexity of its theory knowledge and implementation processes, it makes it difficult for practical engineering application. Furthermore, the characteristic frequency is obtained via the only CS methods, which have shortcomings in the simplicity and intuition [110-112]. The simplified methods will be more conducive to the informative feature from raw signals. In addition, the intelligent approaches will accomplish automatic learning of fault information and the enhanced diagnostic 
performance through using CS as a preprocessing method. In the future, it will be a trend of application for the exploitation of the combined analysis methods to achieve the precise and effective fault diagnosis. It is also worth exploring further to extend the existing approaches to compound faults of the same machinery and diverse rotating machinery.

Author Contributions: Conceptualization, S.T.; Methodology, S.T.; Investigation, S.T.; Writing-Original Draft Preparation, S.T.; Writing-Review and Editing, Y.Z.; Supervision, S.Y. All authors have read and agreed to the published version of the manuscript.

Funding: This work is supported by National Natural Science Foundation of China under grant 51779107 and grant 51805214, National Key Research and Development Program of China (No. 2019YFB2005204), and in part by China Postdoctoral Science Foundation under grant 2019M651722 and Open Foundation of the State Key Laboratory of Fluid Power and Mechatronic Systems (No. GZKF-201905), Natural Science Foundation of Jiangsu Province under grant BK20170548 and the Youth Talent Development Program of Jiangsu University.

Conflicts of Interest: The authors declare no conflict of interest.

\section{Nomenclature}

$\begin{array}{ll}\text { STFT } & \text { short-time Fourier transform } \\ \text { CS } & \text { cyclostationary } \\ \text { WT } & \text { wavelet transformation } \\ \text { CSC } & \text { cyclic spectral correlation } \\ \text { CSCoh } & \text { cyclic spectral coherence } \\ \text { IESAM } & \text { improved envelope spectrum by alpha maximization } \\ \text { IESFOgram } & \text { improved envelope spectrum via feature optimization-gram } \\ \text { SES } & \text { squared envelope spectrum } \\ \text { CSES } & \text { combined squared envelope spectrum } \\ \text { CNN } & \text { convolutional neural network } \\ \text { SNR } & \text { signal-to-noise ratio } \\ \text { SVDD } & \text { support vector data description } \\ \text { NSVDD } & \text { support vector data description with negative samples } \\ \text { EES } & \text { enhanced envelope spectrum } \\ \text { GACS } & \text { generalized almost cyclostationarity } \\ x(t) & \text { random process } \\ L_{i} & \text { any integer } \\ T & \text { sampling period } \\ m_{x}(t) & \text { the first moment of random process } x(t) \\ \tau & \text { the lag time } \\ E\{\} & \text { the mathematical expectation } \\ R_{x}^{\alpha}(\tau) & \text { the cyclic autocorrelation, } \\ \alpha & \text { the cyclic frequency } \\ S_{x}^{\alpha}(f) & \text { the spectral correlation density function or the spectral correlation function } \\ f & \text { the spectral frequency }\end{array}$

\section{References}

1. Li, G.; Tang, G.; Luo, G.; Wang, H. Underdetermined blind separation of bearing faults in hyperplane space with variational mode decomposition. Mech. Syst. Signal. Process. 2019, 120, 83-97. [CrossRef]

2. Lihovd, E.; Johannessen, T.I.; Steinebach, C.; Rasmussen, M. Intelligent diagnosis and maintenance management. J. Intell. Manuf. 1998, 9, 523-537. [CrossRef]

3. Nandi, $\mathrm{S} . ;$ Toliyat, $\mathrm{H} . ; \mathrm{Li}, \mathrm{X}$. Condition monitoring and fault diagnosis of electrical motors-a review. IEEE Trans. Energy Convers. 2005, 20, 719-729. [CrossRef]

4. Nakayama, Y.; Hisano, D.; Kubo, T.; Fukada, Y.; Terada, J.; Otaka, A. TDD-Based Rapid Fault Detection and Recovery for Fronthaul Bridged Network. IEEE Commun. Lett. 2018, 22, 498-501. [CrossRef]

5. Rai, A.; Upadhyay, S.H. Bearing performance degradation assessment based on a combination of empirical mode decomposition and k-medoids clustering. Mech. Syst. Signal. Process. 2017, 93, 16-29. [CrossRef] 
6. Dai, J.; Tang, J.; Huang, S.; Wang, Y. Signal-based intelligent hydraulic fault diagnosis methods: Review and prospects. Chin. J. Mech. Eng. 2019, 32, 75. [CrossRef]

7. He, M.; He, D. A new hybrid deep signal processing approach for bearing fault diagnosis using vibration signals. Neurocomputing 2020, 3965, 542-555. [CrossRef]

8. Randall, R.B. Vibration-Based Condition Monitoring: Industrial, Aerospace and Automotive Applications; John Wiley \& Sons: New Jersey, NJ, USA, 2011.

9. Peng, D.; Smith, W.A.; Randall, R.B.; Peng, Z. Use of mesh phasing to locate faulty planet gears. Mech. Syst. Signal. Process. 2019, 116, 12-24. [CrossRef]

10. Zhou, F.; Chen, J.; He, J.; Bi, G.; Zhang, G.; Li, F. The application review of cyclostationary signal processing in mechanical equipment fault diagnosis. J. Vib. Shock 2006, 25, 148-152.

11. Antoni, J.; Bonnardot, F.; Raad, A.; El Badaoui, M. Cyclostationary modelling of rotating machine vibration signals. Mech. Syst. Signal. Process. 2004, 18, 1285-1314. [CrossRef]

12. Singh, A.; Parey, A. Gearbox fault diagnosis under non-stationary conditions with independent angular re-sampling technique applied to vibration and sound emission signals. Appl. Acoust. 2019, 14415, 11-22. [CrossRef]

13. $\mathrm{Xu}, \mathrm{J} . ; \mathrm{Xu}, \mathrm{K}$. Application of wavelet transform in fault diagnosis of rolling bearings. Chin. J. Mech. Eng. 1997, 33, 50-55.

14. Tang, B.; Liu, W.; Song, T. Wind turbine fault diagnosis based on Morlet wavelet transformation and Wigner-Ville distribution. Renew. Energy 2010, 35, 2862-2866. [CrossRef]

15. Qin, Y.; Mao, Y.; Tang, B.; Wang, Y.; Chen, H. M-band flexible wavelet transform and its application to the fault diagnosis of planetary gear transmission systems. Mech. Syst. Signal. Process. 2019, 1341, 106298. [CrossRef]

16. Xu, T.; Chen, H.; Hu, H. A Low-Complexity Detection Method for Statistical Signals in OFDM Systems. IEEE Commun. Lett. 2014, 18, 632-635. [CrossRef]

17. Teng, Q.; Zhang, L. Data driven nonlinear dynamical systems identification using multi-step CLDNN. AIP Adv. 2019, 9. [CrossRef]

18. Anton, I.; Glossiotis, G. Cyclostationary analysis of rolling-element bearing vibration signals. J. Sound Vib. 2001, 248, 829-845.

19. Randall, R.B.; Antoni, J.; Chobsaard, S. The relationship between spectral correlation and envelope analysis in the diagnostics of bearing faults and other cyclostationary machine signals. Mech. Syst. Signal. Process. 2001, 15, 945-962. [CrossRef]

20. Antoni, J.; Randall, R.B. On the use of the cyclic power spectrum in rolling element bearings diagnostics. J. Sound Vib. 2005, 281, 463-468. [CrossRef]

21. Bennett, W.R. Statistics of Regenerative Digital Transmission. Bell. System Tech. J. 1958, 37, 1501-1542. [CrossRef]

22. Gardner, W.A. The spectral correlation theory of cyclostationary time-series. Signal. Process. 1986, 11, 13-36. [CrossRef]

23. Raad, A.; Antoni, J.; Sidahmed, M. Indicators of cyclostationarity: Theory and application to gear fault monitoring. Mech. Syst. Signal. Process. 2008, 22, 574-587. [CrossRef]

24. Babouri, M.K.; Ouelaa, N.; Kebabsa, T.; Djebala, A. Application of the cyclostationarity analysis in the detection of mechanical defects: Comparative study. Int. J. Adv. Manuf. Tech. 2019, 103, 1681-1699. [CrossRef]

25. Rai, A.; Upadhyay, S.H. A review on signal processing techniques utilized in the fault diagnosis of rolling element bearings. Tribol. Int. 2016, 96, 289-306. [CrossRef]

26. Purushotham, V.; Narayanan, S.; Prasad, S.A. Multi-fault diagnosis of rolling bearing elements using wavelet analysis and hidden Markov model based fault recognition. NDT E Int. 2005, 38, 654-664. [CrossRef]

27. Zhou, Y.; Chen, J.; Dong, G.; Xiao, W.; Wang, Z. Application of the horizontal slice of cyclic bispectrum in rolling element bearings diagnosis. Mech. Syst. Signal. Process. 2012, 26, 229-243. [CrossRef]

28. Dong, G.; Chen, J. Noise resistant time frequency analysis and application in fault diagnosis of rolling element bearings. Mech. Syst. Signal. Process. 2012, 33, 212-236. [CrossRef]

29. Buzzoni, M.; D’Elia, G.; Cocconcelli, M. A tool for validating and benchmarking signal processing techniques applied to machine diagnosis. Mech. Syst. Signal. Process. 2020, 139, 106618. [CrossRef] 
30. Sawalhi, N.; Randall, R.B. Simulating gear and bearing interactions in the presence of faults: Part I. The combined gear bearing dynamic model and the simulation of localised bearing faults. Mech. Syst. Signal. Process. 2008, 22, 1924-1951. [CrossRef]

31. Eugene Arkerjr, B.; Ware, H.A.; Wipf, D.P.; Tompkins, W.R.; Clark, B.R.; Larson, E.C.; Vincent Poor, H. Fault diagnostics using statistical change detection in the bispectral domain. Mech. Syst. Signal. Process. 2000, 14, 561-570. [CrossRef]

32. Antoni, J.; Guillet, F.; El Badaoui, M.; Bonnardot, F. Blind separation of convolved cyclostationary processes. Signal. Process. 2005, 85, 51-66. [CrossRef]

33. Bonnardot, F.; Randall, R.B.; Guillet, F. Extraction of second-order cyclostationary sources-Application to vibration analysis. Mech. Syst. Signal. Process. 2005, 19, 1230-1244. [CrossRef]

34. Antoni, J.; Randall, R.B. A stochastic model for simulation and diagnostics of rolling element bearings with localized faults. J. Vib. Acoust 2003, 125. [CrossRef]

35. Buzzoni, M.; Antoni, J.; Elia, G.D. Blind deconvolution based on cyclostationarity maximization and its application to fault identification. J. Sound Vib. 2018, 432, 569-601. [CrossRef]

36. D'Elia, G.; Cocconcelli, M.; Mucchi, E. An algorithm for the simulation of faulted bearings in non-stationary conditions. Meccanica 2018, 53, 1147-1166.

37. Borghesani, P.; Pennacchi, P.; Ricci, R.; Chatterton, S. Testing second order cyclostationarity in the squared envelope spectrum of non-white vibration signals. Mech. Syst. Signal. Process. 2013, 40, 38-55. [CrossRef]

38. Zhou, F. Study on fault diagnosis method of rolling bearing based on cyclostationary signal processing. J. Shanghai Jiaotong Univ. 2006, 4-10.

39. He, J.; Chen, J.; Bi, G.; Zhou, F. The analysis of frequency modulation principle of cyclostationarity solution and its application in gear fault diagnosis. J. Shanghai Jiaotong Univ. 2007, 11, 1862-1866.

40. Li, M.; Yang, J.; Wang, X. Fault feature extraction of rolling bearing based on an improved cyclical spectrum density method. Chin. J. Mech. Eng. 2015, 6, 1240-1247. [CrossRef]

41. Schmidt, S.; Stephan Heyns, P.; Gryllias, K.C. A pre-processing methodology to enhance novel information for rotating machine diagnostics. Mech. Syst. Signal. Process. 2019, 124, 541-561. [CrossRef]

42. Li, Y.; Ding, K.; He, G.; Jiao, X. Non-stationary vibration feature extraction method based on sparse decomposition and order tracking for gearbox fault diagnosis. Measurement 2018, 124, 453-469. [CrossRef]

43. Zhu, Y.; Tang, S.; Quan, L.; Jiang, W.; Zhou, L. Extraction method for signal effective component based on extreme-point symmetric mode decomposition and Kullback-Leibler divergence. J. Brazilian Soc. Mech. Sci. Eng. 2019, 41, 100. [CrossRef]

44. Lei, Y.; Lin, J.; Zuo, M.J.; He, Z. Condition monitoring and fault diagnosis of planetary gearboxes: A review. Measurement 2014, 48, 292-305. [CrossRef]

45. Zhu, Y.; Qian, P.; Tang, S.; Jiang, W.; Li, W.; Zhao, J. Amplitude-frequency characteristics analysis for vertical vibration of hydraulic AGC system under nonlinear action. AIP Adv. 2019, 9, 035019. [CrossRef]

46. Zhu, Y.; Tang, S.; Wang, C.; Jiang, W.; Yuan, X.; Lei, Y. Bifurcation characteristic research on the load vertical vibration of a hydraulic automatic gauge control system. Processes 2019, 7, 718. [CrossRef]

47. Antoni, J.; Abboud, D.; Xin, G. Cyclostationarity in Condition Monitoring: 10 Years After; ISMA 2016 Including; ISMA USD: Leuven, Belgium, 2016; pp. 2365-2376.

48. Abboud, D.; Baudin, S.; Antoni, J.; Remond, D.; Eltabach, M.; Sauvage, O. The Spectral Analysis of Cyclo-Non-Stationary Signals. Mech. Syst. Signal. Process. 2016, 75, 280-300. [CrossRef]

49. Zhang, X.; Bao, Z. The analysis and processing of non-stationary signal. China Natl. Def. Ind. Press 1998, 325-351.

50. Tang, S.; Yuan, S.; Zhu, Y. Data Preprocessing Techniques in Convolutional Neural Network based on Fault Diagnosis towards Rotating Machinery. IEEE Access. 2020, 8, 149487-149496. [CrossRef]

51. Borghesani, P.; Antoni, J. A faster algorithm for the calculation of the fast spectral correlation. Mech. Syst. Signal. Process. 2018, 111, 113-118. [CrossRef]

52. Kim, Y.C.; Powers, E.J. Digital bispectral analysis and its applications to nonlinear wave interactions. IEEE Trans. Plasma Sci. 1979, 7, 120-131. [CrossRef]

53. Yang, D.-M.; Stronach, A.F.; MacConnell, P.; Penman, J. Third-order spectral techniques for the diagnosis of motor bearing condition using artificial neural networks. Mech. Syst. Signal. Process. 2002, 16, 391-411. [CrossRef] 
54. Wang, H. Analysis and Processing of Nonstationary Random Signals; National Defence Industry Press: Beijing, China, 1999.

55. Gardner, W.A.; Napolitano, A.; Paura, L. Cyclostationarity: Half a century of research. Signal. Process. 2006, 86, 639-697. [CrossRef]

56. Napolitano, A. Cyclostationarity: New trends and applications. Signal. Process. 2016, 120, 385-408. [CrossRef]

57. Napolitano, A. Cyclostationarity: Limits and generalizations. Signal. Process. 2016, 120, 323-347. [CrossRef]

58. Randall, R.B.; Antoni, J. Rolling element bearing diagnostics-A tutorial. Mech. Syst. Signal. Process. 2011, 25, 485-520. [CrossRef]

59. Tang, S.; Yuan, S.; Zhu, Y. Convolutional Neural Network in Intelligent Fault Diagnosis toward Rotatory Machinery. IEEE Access. 2020, 8, 86510-86519. [CrossRef]

60. Kruczek, P.; Obuchowski, J.; Wylomanska, A.; Zimroz, R. On-line updating of cyclostationary tools for fault detection in rotating machines-the filter bank approach. IFAC Pap. 2017, 50, 4702-4707. [CrossRef]

61. Smith, W.; Randall, R.; Du Mee, X.C.; Peng, P. Use of Cyclostationary Properties to Diagnose Planet Bearing Faults in Variable Speed Conditions. In Proceedings of the Tenth DST Group International Conference on Health and Usage Monitoring Systems, Melbourne, Australia, 26-28 February 2017; pp. 1-7.

62. Vamsi, I.; Sabareesh, G.R.; Penumakala, P.K. Comparison of condition monitoring techniques in assessing fault severity for a wind turbine gearbox under non-stationary loading. Mech. Syst. Signal. Process. 2019, 124, 1-20. [CrossRef]

63. Sharma, V.; Parey, A. Extraction of weak fault transients using variational mode decomposition for fault diagnosis of gearbox under varying speed. Eng. Fail. Anal. 2020, 107, 104204. [CrossRef]

64. Mahvash, A.; Lakis, A.A. Application of Cyclic Spectral Analysis in Diagnosis of Bearing Faults in Complex Machinery. Tribol. Trans. 2015, 58, 1151-1158. [CrossRef]

65. Borghesani, P. The envelope-based cyclic periodogram. Mech. Syst. Sig. Process. 2015, 58-59, $245-270$. [CrossRef]

66. Xu, Y.; Zhen, D.; Gu, J.X.; Rabeyee, K.; Chu, F.; Gu, F.; Ball, A.D. Autocorrelated Envelopes for early fault detection of rolling bearings. Mech. Syst. Sig. Process. 2020, 146, 106990. [CrossRef]

67. Li, J.; Yu, Q.; Wang, X.; Zhang, Y. An enhanced rolling bearing fault detection method combining sparse code shrinkage denoising with fast spectral correlation. ISA Trans. 2020. [CrossRef] [PubMed]

68. Zhen, D.; Wang, Z.; Li, H.; Zhang, H.; Yang, J.; Gu, F. An Improved Cyclic Modulation Spectral Analysis Based on the CWT and Its Application on Broken Rotor Bar Fault Diagnosis for Induction Motors. Appl. Sci. 2019, 9, 3902. [CrossRef]

69. Cioch, W.; Knapik, O.; Leskow, J. Finding a frequency signature for a cyclostationary signal with applications to wheel bearing diagnostics. Mech. Syst. Signal. Process. 2013, 38, 55-64. [CrossRef]

70. Qi, J.; Ricardo Mauricio, A.; Gryllias, K. Enhanced particle filter and cyclic spectral coherence based prognostics of rolling element bearings. In Proceedings of the PHM Society European Conference, Utrecht, The Netherlands, 3-6 July 2018; p. 4.

71. Mauricio, A.; Qi, J.; Smith, W.; Randall, R.; Gryllias, K. Vibration based condition monitoring of planetary gearboxes operating under speed varying operating conditions based on cyclo-non-stationary. Analysis 2019, 61, 265-279.

72. Mauricio, A.; Qi, J.; Smith, W.A.; Sarazin, M.; Randall, R.B.; Janssens, K.; Gryllias, K. Bearing diagnostics under strong electromagnetic interference based on integrated spectral coherence. Mech. Syst. Signal. Process. 2020, 140, 106673. [CrossRef]

73. Mauricio, A.; Gryllias, K. Cyclostationary-based multiband envelope spectra extraction for bearing diagnostics: The combined improved envelope spectrum. Mech. Syst. Signal. Process. 2020, 149, 107150. [CrossRef]

74. Antoni, J. Fast computation of the kurtogram for the detection of transient faults. Mech. Syst. Sig. Process. 2007, 21, 108-124. [CrossRef]

75. Barszcz, T.; Jabłon'ski, A. A novel method for the optimal band selection for vibration signal demodulation and comparison with the Kurtogram. Mech. Syst. Sig. Process. 2011, 25, 431-451. [CrossRef]

76. Smith, W.A.; Borghesani, P.; Ni, Q.; Wang, K.; Peng, Z. Optimal demodulation-band selection for envelope-based diagnostics: A comparative study of traditional and novel tools. Mech. Syst. Signal. Process. 2019, 134, 106303. [CrossRef] 
77. Chen, Z.; Mauricio, A.; Li, W.; Gryllias, K. A deep learning method for bearing fault diagnosis based on cyclic spectral coherence and convolutional neural networks. Mech. Syst. Signal. Process. 2020, 140, 106683. [CrossRef]

78. Gao, Y.; Gao, L.; Li, X.; Yan, X. A semi-supervised convolutional neural network-based method for steel surface defect recognition. Robot. CIM INT Manuf. 2020, 61, 101825. [CrossRef]

79. Tang, S.; Yuan, S.; Zhu, Y. Deep learning-based intelligent fault diagnosis methods towards rotating machinery. IEEE Access 2020, 8, 9335-9346. [CrossRef]

80. Antoni, G.; Xin, N.; Hamzaoui, N. Fast computation of the spectral correlation. Mech. Syst. Signal. Process. 2017, 92, 248-277. [CrossRef]

81. Wang, D.; Zhao, X.; Kou, L.-L.; Qin, Y.; Zhao, Y.; Tsui, K.-L. A simple and fast guideline for generating enhanced/squared envelope spectra from spectral coherence for bearing fault diagnosis. Mech. Syst. Signal. Process. 2019, 122, 754-768. [CrossRef]

82. Wang, X.; Yan, X.; He, Y. Weak fault detection for wind turbine bearing based on ACYCBD and IESB. J. Mech. Sci. Technol. 2020, 34.

83. Chen, B.; Zhang, W.; Song, D.; Cheng, Y. Blind deconvolution assisted with periodicity detection techniques and its application to bearing fault feature enhancement. Measurement 2020, 159, 107804. [CrossRef]

84. Ming, A.; Qin, Z.; Zhang, W.; Chu, F. Spectrum auto-correlation analysis and its application to fault diagnosis of rolling element bearings. Mech. Syst. Signal. Process. 2013, 41, 141-154. [CrossRef]

85. Wang, D. Some further thoughts about spectral kurtosis, spectral L2/L1 norm, spectral smoothness index and spectral Gini index for characterizing repetitive transients. Mech. Syst. Signal. Process. 2018, 108, 360-368. [CrossRef]

86. Xu, X.; Zhao, M.; Lin, J.; Lei, Y. Envelope harmonic-to-noise ratio for periodic impulses detection and its application to bearing diagnosis. Measurement 2016, 91, 385-397. [CrossRef]

87. Mo, Z.; Wang, J.; Zhang, H.; Miao, Q. Weighted cyclic harmonic-to-noise ratio for rolling element bearing fault diagnosis. IEEE T. Instrum. Meas. 2020, 69, 2. [CrossRef]

88. Luo, C.; Mo, Z.; Wang, J.; Jiang, J.; Dai, W.; Miao, Q. Multiple discolored cyclic harmonic ratio diagram based on Meyer wavelet filters for rotating machine fault diagnosis. IEEE Sens. J. 2020, 20, 6. [CrossRef]

89. Dalpiaz, G.; Rivola, A.; Rubini, R. Effectiveness and sensitivity of vibration processing techniques for local fault detection in gears. Mech. Syst. Signal. Process. 2000, 14, 387-412. [CrossRef]

90. Capdessus, C.; Sidahmed, M.; Lacoume, J. Cyclostationary processes: Application in gear faults early diagnosis. Mech. Syst. Signal. Process. 2000, 14, 371-385. [CrossRef]

91. Zhang, F.; Appiah, D.; Hong, F.; Zhang, J.; Yuan, S.; Adu-Poku, K.A.; Wei, X. Energy loss evaluation in a side channel pump under different wrapping angles using entropy production method. Int. Commun. Heat Mass. 2020, 113, 104526. [CrossRef]

92. Ha, J.M.; Youn, B.D.; Oh, H.; Han, B.; Jung, Y.; Park, J. Autocorrelation-based time synchronous averaging for condition monitoring of planetary gearboxes in wind turbines. Mech. Syst. Sig. Process. 2016, 70-71, 161-175. [CrossRef]

93. Luo, G.Y.; Osypiw, D.; Irle, M. Real-time condition monitoring by significant and natural frequencies analysis of vibration signal with wavelet filter and autocorrelation enhancement. J. Sound Vib. 2000, 236, 413-430. [CrossRef]

94. Urbanek, J.; Barszcz, T.; Antoni, J. Time-frequency approach to extraction of selected second-order cyclostationary vibration components for varying operational conditions. Measurement 2013, 46, 1454-1463. [CrossRef]

95. Kruczek, P.; Obuchowski, J.; Wylomanska, A.; Zimroz, R. Cyclic sources extraction from complex multiple-component vibration signal via periodically time varying filter. Appl. Acoust. 2017, 126, 170-181. [CrossRef]

96. Wang, Y.; Zhang, F.; Yuan, S. Effect of unrans and hybrid rans-les turbulence models on unsteady turbulent flows inside a side channel pump. ASME J. Fluids Eng. 2020, 142, 061503. [CrossRef]

97. Xin, G.; Hamzaoui, N.; Antoni, J. Extraction of second-order cyclostationary sources by matching instantaneous power spectrum with stochastic model e application, to wind turbine gearbox. Renew. Energy 2020, 147, 1739-1758. [CrossRef]

98. Sun, R.; Yang, Z.; Gryllias, K.; Chen, X. Cyclostationary modeling for local fault diagnosis of planetary gear vibration signals. J. Sound Vib. 2020, 471, 115175. [CrossRef] 
99. Mauricio, A.; Zhou, L.; Mba, D.; Gryllias, K. Vibration-based condition monitoring of helicopter gearboxes based on cyclostationary analysis. J. Eng. Gas. Turbines PowerTrans. ASME 2020, 142, 3. [CrossRef]

100. Mauricio, A.; Qi, J.; Gryllias, K. Vibration Based Condition Monitoring of Wind Turbine Gearboxes Based on Cyclostationary Analysis; ASME Paper No. GT2018-76993; ASME: Washington, DC, USA, 2018.

101. Mauricio, A.; Qi, J.; Gryllias, K. Vibration-Based condition monitoring of wind turbine gearboxes based on cyclostationary analysis. J. Eng. Gas. Turbines Power 2019, 141, 031026.1-031026.8. [CrossRef]

102. Sun, H.; Yuan, S.; Luo, Y. Cyclic Spectral Analysis of Vibration Signals for Centrifugal Pump Fault Characterization. IEEE Sens. J. 2018, 18, 7. [CrossRef]

103. Casoli, P.; Bedotti, A.; Campanini, F.; Pastori, M. A methodology based on cyclostationary analysis for fault detection of hydraulic axial piston pumps. Energies 2018, 7, 1874. [CrossRef]

104. Abboud, D.; Marnissi, Y.; Elbadaoui, M. Optimal filtering of angle-time cyclostationary signals: Application to vibrations recorded under nonstationary regimes. Mech. Syst. Sig. Process. 2020, 145, 106919. [CrossRef]

105. Shi, L.; Zhu, J.; Tang, F.; Wang, C. Multi-Disciplinary Optimization Design of Axial-Flow Pump Impellers Based on the Approximation Model. Energies 2020, 4, 779. [CrossRef]

106. Abboud, D.; Antoni, J. Order-frequency analysis of machine signals. Mech. Syst. Sig. Process. 2017, 87, 229-258. [CrossRef]

107. Abboud, D.; Antoni, J.; Eltabach, M.; Sieg-Zieba, S. Angle \time cyclostationarity for the analysis of rolling element bearing vibrations. Measurements 2015, 75, 29-39. [CrossRef]

108. Lei, Y.; Yang, B.; Jiang, X.; Jia, F.; Li, N.; Nandi, A.K. Applications of machine learning to machine fault diagnosis: A review and roadmap. Mech. Syst. Signal. Process. 2020, 138, 106587. [CrossRef]

109. Liu, Z.; Jin, Y.; Zuo, M.J.; Peng, D. ACCUGRAM: A novel approach based on classification to frequency band selection for rotating machinery fault diagnosis. ISA Trans. 2019, 95, 346-357. [CrossRef]

110. Obuchowski, J.; Zimroz, R.; Wylomanska, A. Identification of cyclic components in presence of non-gaussian noise-application to crusher bearings damage detection. J. Vibroeng. 2015, 17, 3.

111. He, X.; Zhang, Y.; Wang, C.; Zhang, C.; Cheng, L.; Chen, K.; Hu, B. Influence of critical wall roughness on the performance of double-channel sewage pump. Energies 2020, 13, 464. [CrossRef]

112. McCormick, A.; Nandi, A. Cyclostationarity in rotating machine vibrations. Mech. Syst. Signal. Process. 1998, 12, 225-242. [CrossRef]

(C) 2020 by the authors. Licensee MDPI, Basel, Switzerland. This article is an open access article distributed under the terms and conditions of the Creative Commons Attribution (CC BY) license (http://creativecommons.org/licenses/by/4.0/). 